\title{
Factors Influencing Job Satisfaction of Employee in Public Institutions: In Case of Ginnir Town South Eastern Ethiopia
}

\author{
Hussein Yuna ${ }^{1}$ Aliyi Mama Gasu ${ }^{2}$ \\ 1.Department of business administration, faculty of business and leadership lead star university Robe Bale, \\ Ethiopia \\ 2.Department of Environmental Science, College of Natural and Computational Science, Madda Walabu \\ University Robe Bale, Ethiopia.
}

\begin{abstract}
Employee job satisfaction is essential to face the dynamic and ever-increasing challenges of maintaining productivity of the organization by keeping their workforce constantly engaged and motivated. If the employees have negative and unpleasant feelings in the work, their attitudes to the work are dissatisfaction which in turn reduce the achievements of the employee. This paper outlines the employee's job satisfaction level and factors that influence job satisfaction of Employee in public institutions of Ginnir town. The study employed a descriptive survey design where information was gathered mainly using self-administered questionnaires and document analysis. Respondents for the self-administered questionnaires were distributed for all public institutions employees. Hence, all 257 employees were selected. Data presentation was used different tools such as tables, bar charts and pie charts and analyzed using descriptive statistics. The findings of the study showed that general job satisfaction levels of employees in the organizations are inclining towards negative in all criteria. In terms of main factors, the responses show that employees are dissatisfied with self-improvement, opportunities and "working conditions. Besides poor job satisfaction conditions the study also identifies factors that affect job satisfaction like salary level, internal facility, upgrade employees' knowledge and skills, organizational recognition and awards, annual bonus payment, perceiving promotion and grade as fair, sponsorship to pursue academic and professional education programs and the like. Further the study identifies effects of job dissatisfaction in Ginnir town as turnover, absenteeism, tardiness, Accidents, Strikes, Grievances and Sabotage. The study recommended extensive and sustained improvement about the job satisfaction levels of the important factors.
\end{abstract}

Keywords: Employees, Factors, Ginnir, Job Satisfaction

DOI: $10.7176 / \mathrm{EJBM} / 11-16-07$

Publication date:June $30^{\text {th }} 2019$

\subsection{INTRODUCTION:}

Job satisfaction is defined as an individual's psychological state, feelings and attitudes in terms of intrinsic and extrinsic components, towards of jobs and institutions they work in it. The components of job satisfaction are interrelated to payment, promotion, benefits, work nature, supervision, and relationship with colleagues (Mosadeghard, 2003).

The human resources are without doubt the most essential asset in organization for success. Managers in organizations usually stimulate satisfaction of their employees at work to extend effort to performance by making them satisfied and share success together (Adeyinka et al., 2007).

Job satisfaction is worth to be investigated and very important to be kept at high level in public institutions because, employee's job satisfaction is considered as a significant achievement aspect for organizations.

Boyens (2007) said that the two types of turnover are the most devastating for organizations. The effect of voluntary turnover includes loss of performance, knowledge, expertise, relationship, and loss of the time and resources that it took to train the employee. This leads to a feeling of insecurity and affects the performance of the employees who are left because of the constant disruption of services and too much change which as a result affects the general performance of the company.

In recent decades, this subject has stimulated interest in Ethiopia as well. Employee satisfaction would also advance investor's confidence, as they are concerned with organization's capacity to carry out in such ways that would positively influence the value of their investment in the organization, hence there is no question that uncontrolled employee turnover could damage the stability of the organization (Miller, 2006).

Due to the dissatisfied nature of attitude of employees, the mining sector in the locality has challenges with high labor turnover, low commitment of employees, high absenteeism rate, labor unrest and subsequent low productivity (Griffeth, R.,et.al, 2000) .

In recent times of frequent corporate restructuring and swift change in technology, organizations that want to remain competitive and outwit rivals must maintain employees who are open to innovation and to changing roles. Nevertheless, employees will be more adaptable, corporative and productive if they are satisfied with their job. As a result, it has therefore become imperative that management in organizations must understand how to enhance job satisfaction within their rim(s) of operation to improve performance level for organizational sustainability. It 
is therefore appears that employees are dissatisfied and are not performing to achieve target. It is on this score that it has become necessary to assess the effect of job satisfaction on employees' performance in mining organizations in the district (Miller, 2006).

Hence, when employees are not satisfied, it can lead to high attrition rates and low productivity. A satisfied employee often equates to a productive employee. A productive employee equates to a productive and happy company. So job satisfaction and employee contentment be supposed to be a big aspiration in talent management due to its impact on effectiveness, creativity and loyalty of employees. Talented employees desire a clear vision of where the organization is going and an opportunity to personally grow and develop. Employees want to feel that their talent and skill enables them to develop in a certain organization through opportunities for growth. Absence of this leads to dissatisfaction and poor performance. This is currently the case at Ginnir town public institutions.

In my looking for research, unfortunately, I could not observe the research that made even in Ethiopia major governmental institutions about job satisfaction. Particularly, the public sectors, those derive the country's strategy and pillars for providing good governance services to the people. So the intention of this study is to identify employee's job satisfaction level and factors that influence job satisfaction of Employee in public institutions of the town in order to recommend the public institution to take necessary steps to keep the employees satisfaction with their work and other work-related factors for the success of the institutions.

\subsection{METHODOLOGY}

\subsection{Description of the Study Area}

Ginnir town is found in Bale zone, Oromia regional State in Federal Democratic Republic of Ethiopia. It is located at $136 \mathrm{Km}$ East to Robe, the capital city of Bale zone, while at $545 \mathrm{~km}$ South East to Finfine, the capital city of Ethiopia. It was established in 1884 G.C, 5 years before establishment of Finfine city, in 1889, on 2416 hectare catchment area. Ginnir town was the main town of Ginnir woreda until 6 July 2013, since 7 July 2013 it has been separated from Ginnir woreda \& recognized to be one of the " $2^{\text {nd }}-\mathrm{B}$ level " town of the oromia's regional state. It is enclosed by 7 villages of Ginnir woreda, namely, at the direction of North-Jame, South- Ashute-Gaguro and Chancho villages, East- Oda-Roba and Ardaterre villages, and at the West direction Lobocha and Ebisa villages. Now a day, Ginnir town has 26 public sectors.

According to the 2017-2018 Ginnir municipality profile, there are 8120 Household heads with the total population of 41,113 while 20,639 are male and the remained 20,474 are female. Climatically its condition is temperate with its altitude of $1700 \mathrm{~m}-2203 \mathrm{~m}$ above the sea level, average annual rain fall is 7,501,280.3 MM, while its annual temperature is $15^{\circ} \mathrm{c}-20^{\circ} \mathrm{c}$ and its wind direction is from the North West.

Agricultural, commercial and hand crafts are the main economic activities in the town.

\subsection{Research Design}

The study was utilized descriptive survey design, seeking to evaluate extent of employees' satisfaction and factors that influence their satisfaction in public institutions by studying a sample. The researcher preferred Survey research approach since it is best method to explore in depth a program, event, activity, process or phenomena accurately. Furthermore, survey approach can provide very engaging and rich explorations of a program or application as it develops in a real-world setting by using both quantitative and qualitative research method. Crosssectional survey was carried out to collect the primary data in a simpler manner and as per the activity schedule set in the research proposal.

\subsection{Sampling Technique}

First of all, all 26 public institutions in the town were selected. Then the researcher was selected all 257 employees in public institutions as respondents so as to address all the employees.

\subsection{Method of data collection}

The study was based on both secondary and primary data sources. It was begun by secondary data analysis through the detailed review of related literature. To this end; books, articles, journals, magazines and bulletins were reviewed.

Primary information about the level of employees' satisfaction in public institutions was obtained through open-ended and closed-ended questionnaires.

The questionnaire comprises three sections. Section I contains demographical questions about the respondents including sex, age, years of work experience, length of service with the organization and educational level. Section II items incorporates; perceptual responses pertaining to provision of training and development, growth and development opportunities, workplace learning issues and management's supervision and guidance. And section III items incorporate open ended questions which require respondents to give their explanation. 


\subsection{Method of Data Analysis}

The data analysis of the study is done in a way that its objectives demand. As much as possible, separate analysis for individual objectives is done. Demographic characteristics are summarized using frequencies and percentages for all variables including: age, sex, work experience, years on the current job/position and educational level. In employees' satisfaction analysis; the data gathered through questionnaires were analyzed and presented in the form of charts, diagrams and tables using SPSS software.

The results of the interview questions were integrated to the responses of employees through questionnaires and were analyzed accordingly.

\subsection{Data Preparation(Data quality control)}

Even though hundred percent data quality is a myth, it is better to achieve data quality as much as possible. Starting from the beginning it needs commitment, applying all the steps and tools in the research process, during survey and data analysis, the researcher was prepared self-checking questions, inspection and continued monitoring of enumerators during survey. Then the collected data was safely organized, coded and input into SPSS as per its analytical need. Then it was checked before analytical operation has been run.

Therefore the researchers were investigated and describe the study topic by using valid, accurate and reliable data in order to achieve the objectives of the study and to have decision makers and other researcher's confidence and rely up on the data. Hence, the researchers were measure the data quality in terms of validity, reliability and practicability.

\subsection{RESULTS AND DISCUSSION}

3.3.1. Level of Employees job satisfaction

3.3.1.1. Feeling of the respondents about their job

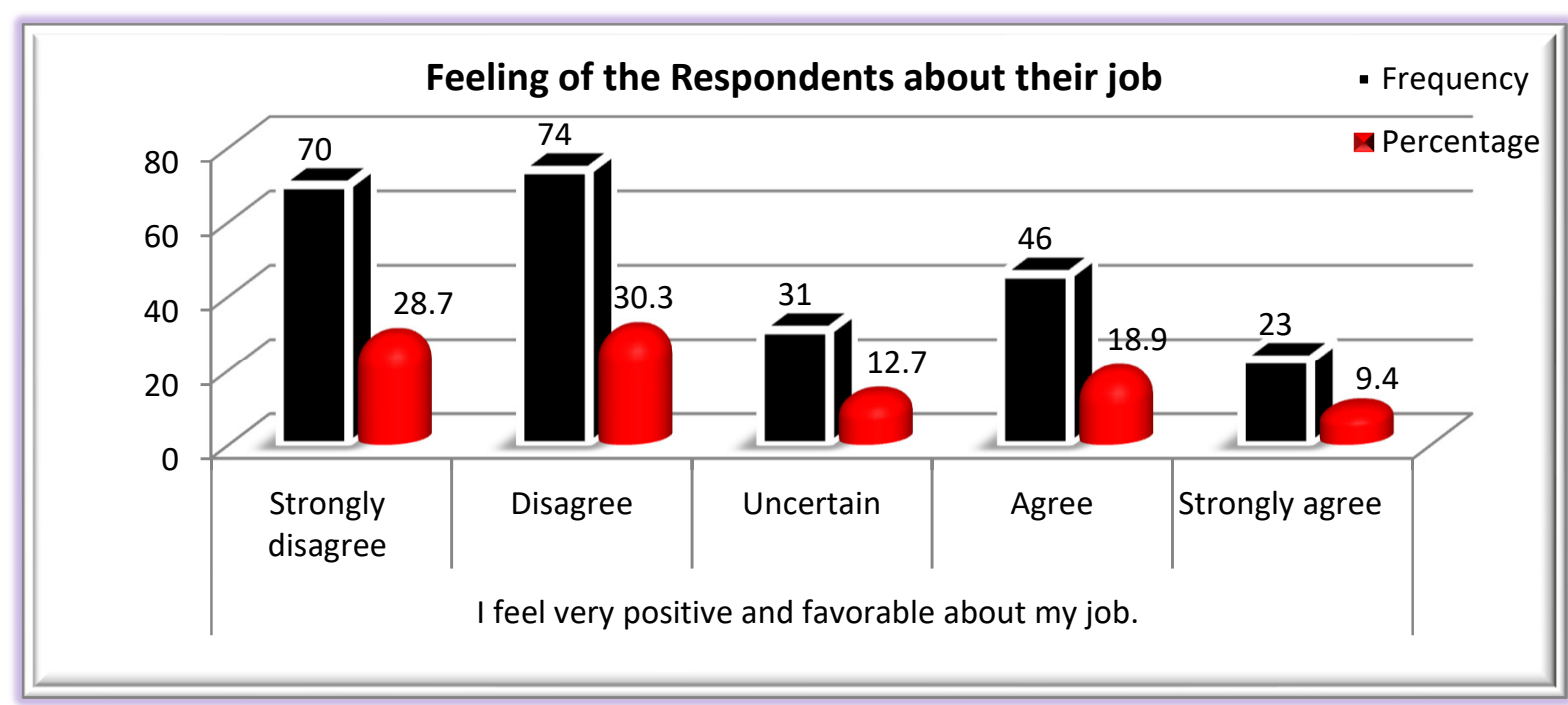

Figure 1: Feeling of the respondents about their job.

Source: Compiled by researcher from the Questionnaires (2018)

As shown in (Figure 1), respondents were asked to indicate the overall Feeling of their job whether they are very positive and favorable on their job or not. Hence, $28.3 \%$ of respondents responded as they are not feeling positive and favorable about their job, $12.7 \%$ of respondents responded as they are uncertain and $59 \%$ of the respondents feel positive and favorable about their job. 


\subsubsection{Interest to leave/Quit current job}

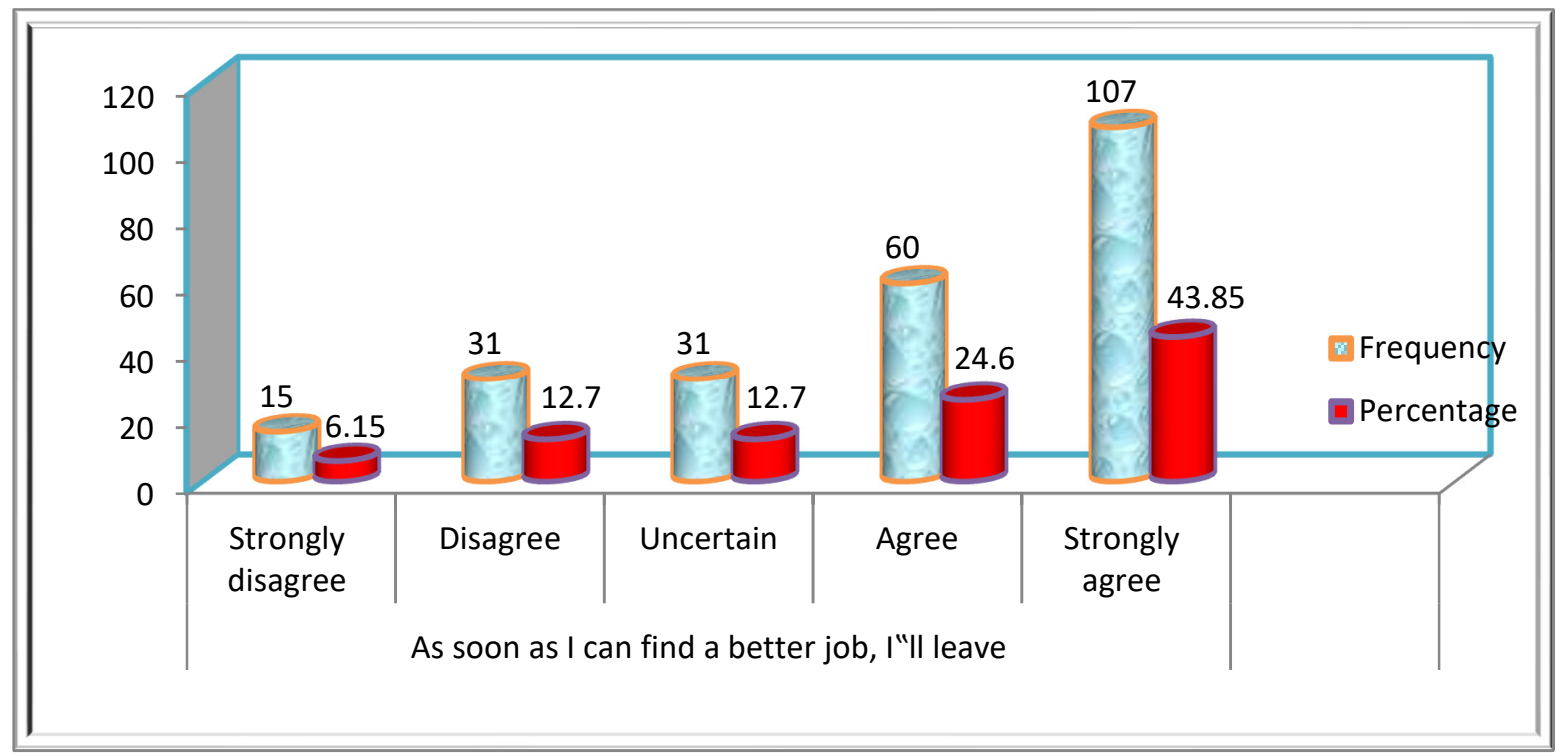

Figure 2: Interest to leave current job

Source: Compiled by researcher from the Questionnaires (2018)

As shown in (Figure 2), respondents were asked to indicate their overall interest on their job and then $18.85 \%$ of the respondents said as they are not ready to resign from their job, $12.7 \%$ of them are uncertain and $68.45 \%$ of the respondents stated as they are ready to resign from their job.

\subsubsection{Satisfaction with the kind of work}

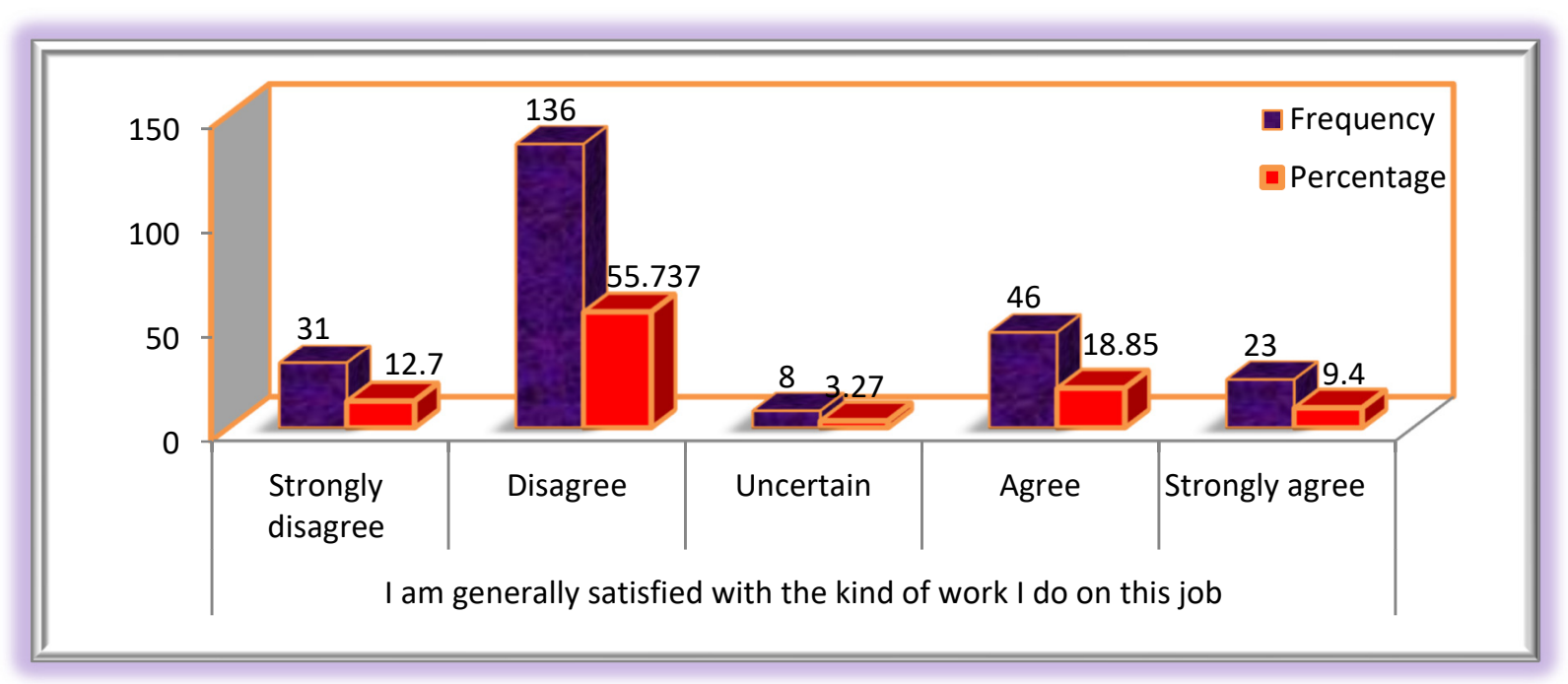

Figure 3: Satisfaction with the kind of work

Source: Compiled by researcher from the Questionnaires (2018)

As shown in (Figure 3), respondents were asked to indicate whether they are satisfied with the kind of work they are doing and then $68.44 \%$ of respondents are dissatisfied with the kind of work, $3.27 \%$ of them are uncertain and $28.25 \%$ of them are satisfied. 


\subsubsection{Frequency of thinking about quitting job}

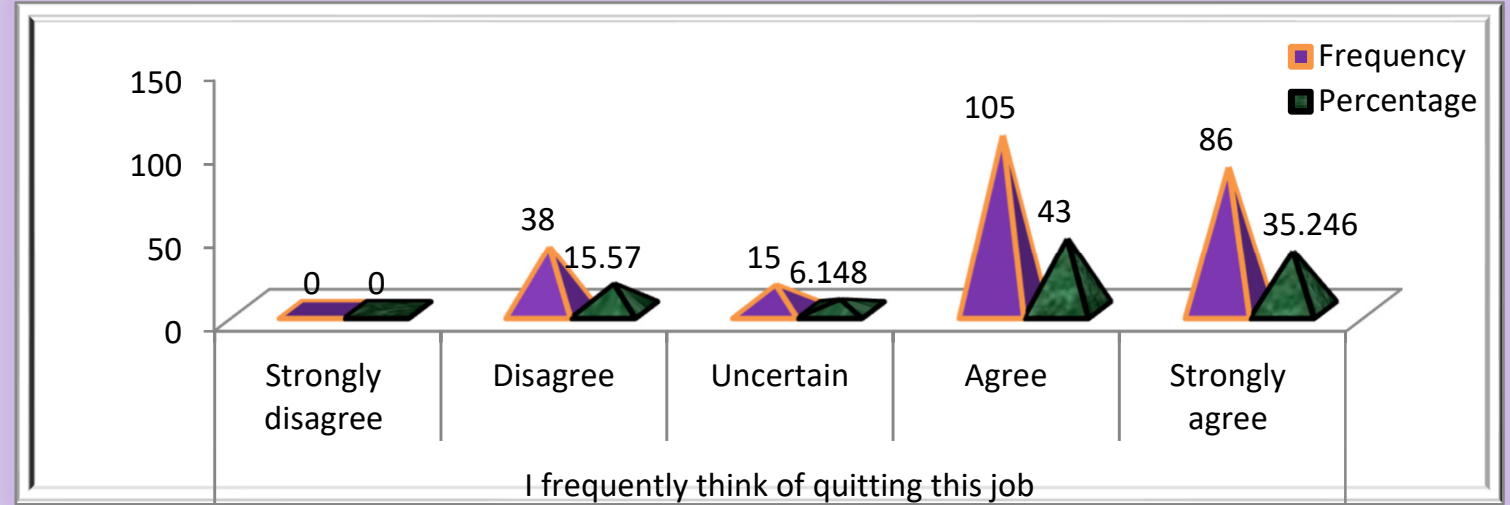

Figure 4: Frequency of thinking about quitting job

Source: Compiled by researcher from the Questionnaires (2018)

As shown in (Figure 4), respondents were asked to indicate whether they are frequently thinking of quitting their job or not and then $15.57 \%$ of respondents said as they are not thinking of quitting their job, $6.15 \%$ of them are uncertain and $78.25 \%$ of them are thinking Frequency about quitting job.

\subsubsection{Sense of worthwhile to accomplish work}

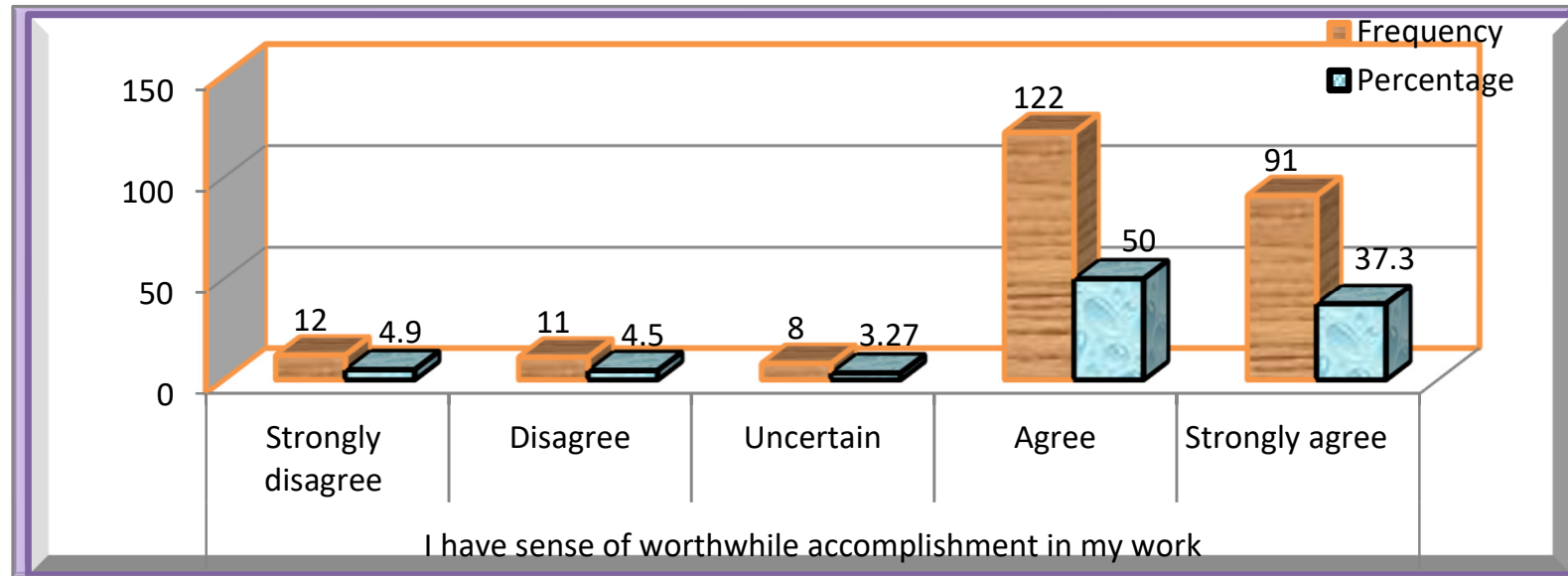

Figure 5: Sense of worthwhile to accomplish work

Source: Compiled by researcher from the Questionnaires (2018)

As shown in (Figure 5), respondents were asked to indicate whether they are sense of worthwhile to accomplish their work or not, $9.4 \%$ are stated as they have no sense of worthwhile to accomplish work, $3.27 \%$ of them are uncertain and $87.3 \%$ of them have sense of worthwhile to accomplish their work.

3.3.1.6. Chance to take decisions on the performance of job role

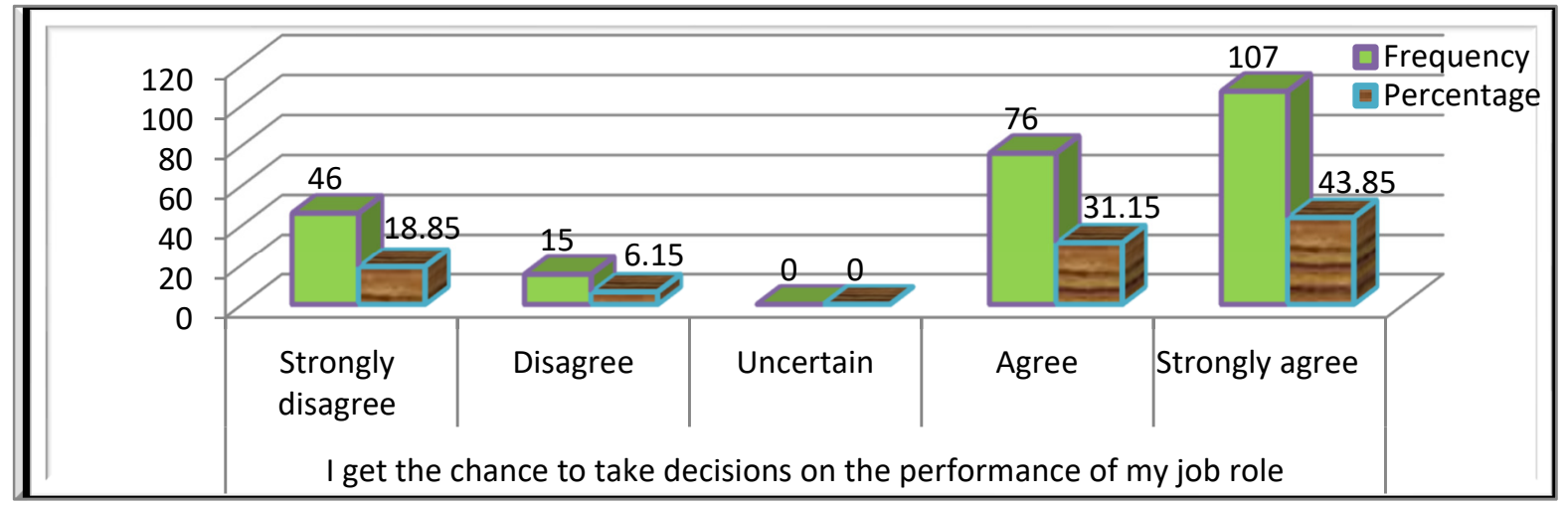

Figure 6: Chance to take decisions on the performance of job role

Source: Compiled by researcher from the Questionnaires (2018) 
As shown in (Figure 6), respondents were asked to indicate whether they get the chance to take decisions on the performance of job role or not. Then of the total respondents, $25 \%$ of them are responded as they didn't get the chance to take decisions on the performance of job role, $75 \%$ of them agreed as they get the chance to take decisions on the performance of job role.

Again most of the employees don't think they are paid well enough, they may start looking for another opportunity soon.

\subsubsection{Factors that affect employee's satisfaction}

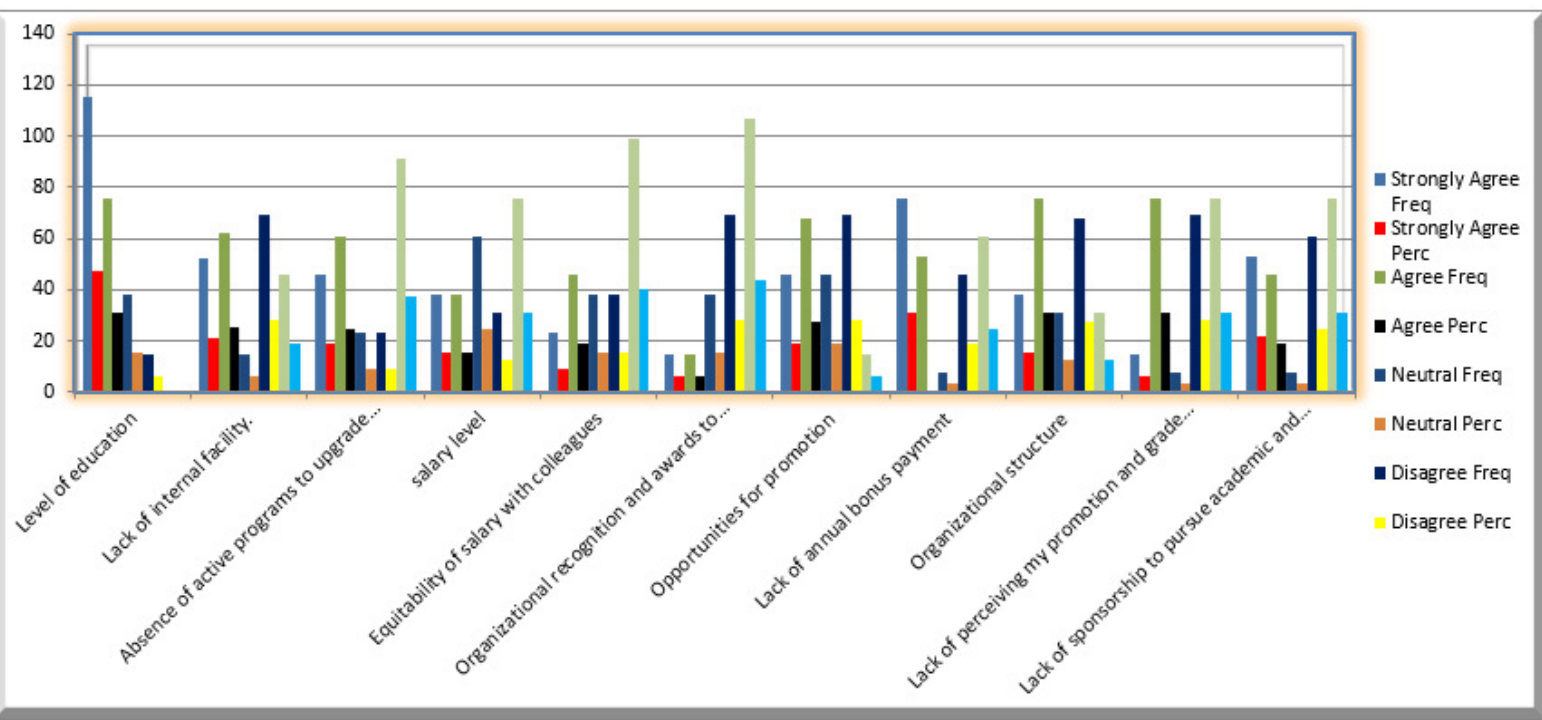

Figure 7: Factors that affect employee's satisfaction

Source: Compiled by researcher from the Questionnaires (2018)

As shown in (Figure 7), respondents were asked to indicate factors that affect employee's satisfaction, then $78.28 \%$ of the respondents agreed as Level of education is factors that affect employee's satisfaction, $15.57 \%$ of them are uncertain and $6.15 \%$ of them disagreed as Level of education is factors that affect employee's satisfaction. On the other hand, for factors like Lack of internal facility $(46.72 \%$ are agreed, $6.15 \%$ uncertain and $47.13 \%$ are disagreed ); for absence of active programs to upgrade employees' knowledge and skills (43.85\% are agreed, 9.42\% uncertain and $46.73 \%$ are disagreed); for salary level $(31.14 \%$ are agreed, $25 \%$ uncertain and $43.86 \%$ are disagreed ); for Equitability of salary with colleagues (28.28\% are agreed, $15.57 \%$ uncertain and $56.14 \%$ are disagreed ); for organizational recognition and awards to employees (12.3\% are agreed, $15.57 \%$ uncertain and $72.12 \%$ are disagreed); for opportunities for promotion (46.72\% are agreed, $18.85 \%$ uncertain and $34.43 \%$ are disagreed); for lack of annual bonus payment (52.85\% are agreed, 3.3\% uncertain and $43.85 \%$ are disagreed); for organizational structure (46.72\% are agreed, $12.71 \%$ uncertain and $40.57 \%$ are disagreed); for lack of perceiving promotion and grade as fair (37.29\% are agreed, 3.3\% uncertain and 59.41\% are disagreed); Lack of sponsorship to pursue academic and professional education programs $(40.55 \%$ are agreed, $3.3 \%$ uncertain and $56.15 \%$ are disagreed ).

Mean while, from open ended questionnaire most of the respondents stated as Workplace flexibility, retirement plans, paid leave, and other benefits can be key factors that affect job satisfaction.

\subsubsection{Effects of Job Dissatisfaction}

Table 1: Effects of Job Dissatisfaction

\section{Effects}

$\begin{array}{ll}\text { Turnover } & 56 \\ \text { Absenteeism } & 16 \\ \text { Tardiness } & 38 \\ \text { Accidents } & \\ \text { Strikes } & \\ \text { Grievances } & \\ \text { Sabotage } & 3\end{array}$

Source: Compiled by researcher from the Questionnaires (2018)

As shown in (Table 1), respondents were asked to indicate the effects of job dissatisfaction and then of the total respondents $23 \%$ of them stated as it causes turnover, $6.5 \%$ of them stated as it causes absenteeism, $15.57 \%$ of them stated as it causes Tardiness, $16.4 \%$ of them stated as it causes Accidents, $3.69 \%$ of them stated as it causes Strikes, $13.12 \%$ of them stated as it causes Grievances and $21.72 \%$ of them stated as it causes Sabotage. 


\subsection{CONCLUSIONS}

According to the descriptive analysis of the result, it is seen that general job satisfaction level of employees is less. In terms of main factors, the responses show that employees are dissatisfied with self-improvement, opportunities and "working conditions. Another result about this study is that satisfaction levels, although "communication and cooperation with co-workers" are somewhat satisfied factors among all job satisfaction determinants, employees do not satisfied by many factors like (salary level, internal facility, upgrade employees' knowledge and skills, organizational recognition and awards, annual bonus payment, perceiving promotion and grade as fair, sponsorship to pursue academic and professional education programs) and the like. Again they claim that they do not think that they have a chance to choose a department in which they prefer to work. Maybe, when employees start to work, before the assignments, employees characteristic specialties should be taken into consideration. Salary level has the highest level of percent dissatisfaction ratio among all factors. The results indicate that further work-related salary level should be followed strictly by level of education the institution like for equitability of salary with colleagues. Also, they think that some improvements need to be considered by the institution for more comfortable physical conditions.

Hence, it is found that most of the employee's are not satisfied. In each and every criterion like job satisfaction, their acquaintance on vision and mission, their confidence on leadership, and their value in the organization and out of all, the most important is that the majority of employee feels inferior to work in the organization. Regarding working environment, most of the employees feel that their surrounding environment is not safe to work because they have responded negatively in all decisive factors like working conditions and physical environment.

\subsection{RECOMMENDATIONS}

Hopefully; the recommendations of this thesis will be able to help the institution to take necessary steps for improvement about the job satisfaction levels of the important factors.

The institution is required to pay attention to job satisfaction of employees, by concerning specific differences by employee demographics such as gender, educational level, and seniority.

Despite the fact that greater part of the employees are disappointed and some are in a neutral category (a vague condition) in this way, management/ authority of the organization ought to reevaluate about disappointment factors ( causes and reasons), and can diminish issues so that in future can accomplish $100 \%$ worker satisfaction level.

The results also suggest that organizational leaders can participate more and create pro employee attitude as medium to generate positive organizational result.

For the future studies, the presented system with the surveys and analyses in this thesis would be reapplied in certain periods and the necessary steps could be taken by authorized managers and departments.

\subsection{REFERENCES}

Boyens, M. (2007). Organizational socialization, career aspirations and turnover intentions among design engineers. Leadership and Organization Development Journal, Emerald Group Publishing Limited, Vol. 26 (6) pp 424-441.

Cappelli, P. (2008). Talent on Demand: Managing Talent in an Age of Uncertainty. Boston, MA Harvard Business School Press.

Freyermuth, B. (2004). Performance Appraisal Satisfaction and Employee Outcome: Mediating and Moderating roles of work motivation. International Journal of Human Resource Management, Vol. 17 (3).

Ginnir town municipality report, (2018), Unpublished

Griffeth, R., Shore L., \& Allen, G. (2000). The role of perceived organizational support and supportive Human Resource Practices in the Turnover Process. Journal of Management, Vol. 29 (99).

Hausknecht, P., Rodda,.M. \& Howard,.J. (2009). Targeted Employee Retention: Performance Based and JobRelated differences in reporting reasons for staying. Center for Advanced Human Resource Studies, Cornell University.

Johnson, J, Griffeth, W., \& Griffin, M. (2000). Factors discrimination functional and dysfunctional sales force turnover. Journal of Business \& Industrial Marketing, Vol. 15 (6) pp. 399-415.

Kuria E. (2011) Factors influencing the level of job satisfaction of the deputy head teachers of the public secondary schools in Kenya. Un published thesis: Kenyatta University

Lee, H. (2003). An empirical study of organizational justice as a mediator of the relationship among leader-member exchange and job satisfaction, organizational commitment and turnover intentions in the lodging industries.

Lee-Kelley, L., Blackman, A., \& Hurst, P. (2009). An Exploration of the Relationship Between Learning Organisations and the Retention of Knowledge Workers.” The Learning Organization, Volume 14: 3: 204221.

McCrea, B. (2001). When good employees retire. Industrial Distribution, March 2001, pp. 6366.

Mello, J.A. (2007). Strategic Human Resource Management. (2nd ed.), India: Cengage South Western. 
Meyer, J. \& C. Smith, (2003). HRM practices and organizational commitment: Test of a mediation model. Canadian Journal of Administrative Sciences, 17: pp 319-331.

Mitchell, R., Holtom, C., \& Lee, W. (2001). How to Keep Your Best Employees: Developing an Effective Retention Policy. Academy of Management Executive, 15 (4) pp 96-107.

Ongori, H. (2008). A review of the Literature on Employee Turnover. African Journal of Business Management, Vol. 1 (3) pp 1-54.

Prince, J. (2005). Career-focused employee transfer processes. Career Development International, 10(4), $293-309$.

Ongori, H. \& Agolla J. (2009). Paradigm shift in managing career plateau in organization: The best strategy to minimize employee intention to quit. African Journal of Business Management, Vol.3 (6), pp. 268-271.

Shahzad, K., Rehman, K. \& Abbas, M. (2010). HR Practices and Leadership Styles as Predictors of Employee Attitude and Behaviour. European Journal of Social Sciences, Vol. 14 November 2010.

Simatwa EMW (2011). Job Satisfaction and Dissatisfaction among Teachers in Kenya. Kenya Journal of Education Planning Economics and Management. Vol.3 (3) 114-123 (ISSN; 2074-5400).

Steel, R. \& Griffeth, W. (2002). The elusive relationship between perceived employment opportunity and turnover behavior: A methodological or conceptual artifact. Journal of Applied Psychology, 74(6): pp 846-854.

Sutherland, M. (2004). Factors affecting the retention of Knowledge Workers. PhD Dissertation, Faculty of Economics and Management Sciences, University of Johannesburg.

Taylor, R. (2004). The Race for Talent: Retaining and Engaging Workers in the 21 st Century. Human Resource Planning Journal, Vol. 27 (3) pp 12-46.

Woodruffe, C. (1999). Winning the talent war: A strategic approach to attracting, developing and retaining the best people. Chichester, UK: John Wiley \& Sons.

Wright, M., Gardner, M., Moynihan, M. \& AllenR. (2005). The relationship between HR practices and firm performance: examining causal order, Personnel Psychology, 58, (2) pp 409-46.

Yamamoto, H. (2006). The relationship between employeese inter-organizational career orientation and their career strategies. Career Development Journal. 11 (3): pp 243-264.

Young, T. (2006). Implementing a knowledge retention strategy. Knowledge Management Review, Vol 9, issue 5, pp. 28-33, November/December 2006. 